\title{
Structural and mechanical properties of cellulose acetate/graphene hybrid nanofibers: Spectroscopic investigations
}

\author{
M. Gopiraman ${ }^{1}$, K. Fujimori ${ }^{1}$, K. Zeeshan ${ }^{1}$, B. S. Kim ${ }^{2 *}$, I. S. Kim ${ }^{1}$ \\ ${ }^{1}$ Nano Fusion Technology Research Group, Interdisciplinary Graduate School of Science and Technology, Ueda, \\ 386-0015 Nagano, Japan \\ ${ }^{2}$ Department of Organic Materials \& Fiber Engineering, Chonbuk National University, 567 Baekje-daero, Deokjin-gu, \\ Jeonju-si, 561-756 Jeollabuk-do, Republic of Korea
}

Received 20 December 2012; accepted in revised form 12 March 2013

\begin{abstract}
Cellulose acetate/graphene (CA/graphene) and cellulose acetate/graphene-COOH (CA/graphene-COOH) hybrid nanofibers were fabricated via electrospinning technique, and their morphologies, crystallinity and mechanical properties were investigated. The added amounts of graphene and graphene-COOH were varied from 0.5 to $5.0 \mathrm{wt} \%$. The crystal structures and morphologies of the resultant hybrid nanofibers were investigated by wide angle X-ray diffraction (WAXD), scanning electron microscopy (SEM) and transmission electron microscopy (TEM), respectively. Graphene-COOH incorporated CA nanofiber mats showed higher Young's modulus of about $910 \mathrm{MPa}$ among than those of CA/graphene nanofibers, which is due to molecular interactions between $-\mathrm{COOH}$ groups in acid-treated graphene and $\mathrm{C}=\mathrm{O}$ groups in $\mathrm{CA}$ via hydrogen bonding. This specific interaction was demonstrated by spectroscopic studies (Raman and Fourier transform infrared (FT-IR) spectroscopies).
\end{abstract}

Keywords: mechanical properties, nanofiber, graphene, molecular interactions, polymer composites

\section{Introduction}

In order to avoid the environmental pollutions by synthetic polymeric materials, in the recent few decades, the number of reports of the biodegradable polymers or green composites has been rapidly growing [1-5]. Certainly, electrospinning is a simple and very effective technique for the fabrication of nanofibers and nanocomposite fibers [6]. In particular, the fabrication of nanofibers using cellulose and its derivatives has played important role due to their excellent properties [7], especially due to their biodegradability in nature [8-11]. Moreover, due to potential compatibility, excellent optical and mechanical properties, cellulose acetate (CA) has been used for the applications in diverse areas such as fibers, films, laminates, adhesives, coatings, plastic products, etc. [12-16]. In fact, the significant amounts and varieties of synthetic plastics, especially polyolefins, polystyrene (PS), etc. are currently produced from fossil fuels, consumed and discarded into the environment, ending up as nondegradable wastes. Their disposal by burning produces a considerable increase in carbon dioxide $\left(\mathrm{CO}_{2}\right)$ and, in some cases, toxic gases, which contribute to global pollution or green house effects. As a result, there is considerable interest in biodegradable polymers, which can be used as alternatives to traditional plastics, thus reducing the amount of wastes. Hence in order to control environmental pollution, researchers have been paid attention to green composites/fibers.

\footnotetext{
${ }^{\text {*Corresponding author, e-mail: kbsuhk@yahoo.com }}$

(C) BME-PT
} 
Incorporation of electrically conductive nano-additives, such as carbon nanotubes (CNTs) and High Purity Graphene (HPG) [17], into these fibers can both improve mechanical properties and enable the multi-functionality needed for electrical energy storage [18], sensing [19], and actuation [20]. Many of the possible applications would greatly benefit from increased fiber toughness, which is the ability to absorb mechanical energy before rupture. Most importantly, the dispersion of carbon nanomaterials into the polymer matrices has been the subject of intensive research during the last decade [21-27]. The wonderful prospective of graphene nanoplatelets inside the polymer matrices has generated much interest among researchers. Because of their unique mechanical and electrical properties [2930], the carbon materials incorporated hybrid nanofibers give much more interests to study their morphologies and to improve the mechanical and electrical properties.

In this work, we report the morphologies, crystal structures and mechanical properties of $\mathrm{CA} /$ graphene and $\mathrm{CA}$ /graphene- $\mathrm{COOH}$ hybrid nanofibers measured by scanning electron microscopy (SEM), transmission electron microscopy (TEM) and X-ray diffraction (XRD), respectively. FT-IR and Raman spectroscopy were carried out for the resultant hybrid nanofibers to confirm the interactions between polymer matrix and graphene or graphene- $\mathrm{COOH}$ nano-additives.

\section{Experimental section}

\subsection{Materials}

Cellulose acetate (CA, 39.8\% acetyl content, average $M_{\mathrm{w}}=30 \mathrm{kDa}$ ) were obtained from Aldrich Chemical Company. Graphene with an average particle size of $800 \times 300 \mathrm{~nm}$, thickness of $5 \mathrm{~nm}$, surface area of $150 \mathrm{~m}^{2} / \mathrm{g}$, and a purity of $>99 \%$ (Graphene150) were kindly supplied from Quantum Materials Co., India. DMF and acetone were purchased from Wako pure chemicals, Japan, and used directly without further purification.

\subsection{Electrospinning}

A high-voltage power supply (Har-100*12, Matsusada Co., Tokyo, Japan), capable of generating voltages up to $80 \mathrm{kV}$, was used as the source of the electric field. The CA solutions were made from CA $2.345 \mathrm{~g}$, acetone $6.0 \mathrm{~g}$, and DMF $4.0 \mathrm{~g}$. The concentration of CA solutions was $19 \mathrm{wt} \%$. In order to improve the solubility of the CA polymer in acetone/DMF mixture, the $\mathrm{CA}$ solutions were heated to about $60^{\circ} \mathrm{C}$ for 2 hours and then this CA solutions were supplied through a plastic syringe attached to a capillary tip with an inner diameter of $0.6 \mathrm{~mm}$. The copper wire connected to a positive electrode (anode) was inserted into the CA polymer solution, and negative electrode (cathode) was connected to a metallic collector. The voltage was fixed at $12 \mathrm{kV}$ and the distance between the capillary tip and the collector was $15 \mathrm{~cm}$.

\subsection{Preparation of $\mathrm{CA} / \mathrm{graphene}$ and $\mathrm{CA} /$ graphene-COOH hybrid nanofibers}

In order to prepare the $\mathrm{CA} /$ graphene hybrid nanofibers, the dispersion of graphene was prepared in acetone/DMF ( $6: 4$ by weight) mixture $(2.0 \mathrm{~g})$ under sonication for $30 \mathrm{~min}$, and CA (2.345 g) was dissolved in acetone/DMF (6:4 by weight) mixture $(8.0 \mathrm{~g})$ by stirring at $60^{\circ} \mathrm{C}$, respectively. For the fabrication of graphene incorporated CA hybrid nanofibers, CA solution $(8.0 \mathrm{~g})$ was mixed with graphene solution $(2.0 \mathrm{~g})$ described above and stirred for $10 \mathrm{~min}$ after sonicating for $30 \mathrm{~min}$. This process was repeated three times. The $\mathrm{CA} /$ graphene- $\mathrm{COOH}$ hybrid nanofibers were also obtained using the same strategy. The concentrations of graphene and graphene-COOH were 0.5, 1.0, $2.03 .0,4.0$ and $5.0 \mathrm{wt} \%$, respectively. All solutions were electrospun onto a rotating metallic collector at room temperature under identical conditions.

\subsection{Characterization}

The morphologies of hybrid nanofiber mats were observed by scanning electron microscopy (SEM S3000N, HITACHI, Japan). Transmission electron microscopy (TEM) (JEM-2100 JEOL Japan, accelerating voltage $120 \mathrm{kV}$ ) was used to investigate the dispersion and alignment of the graphene and graphene- $\mathrm{COOH}$ in the resulting $\mathrm{CA} /$ graphene and $\mathrm{CA} /$ graphene- $\mathrm{COOH}$ hybrid nanofibers. At least more than 100 fiber measurements form SEM images were used in order to ensure reproducible statistics when measuring fiber size distributions. Fiber diameters were measured by image processing software (Image J, NIST). The Raman spectra were recorded with a Raman spectrometer (Hololab 5000, Kaiser Optical Systems Inc., USA), and argon laser at $532 \mathrm{~nm}$, with a Kaiser holographic edge filter. The wide-angle X-ray diffraction (WAXD) experiments 
were performed at room temperature with hybrid nanofiber samples using a Rotaflex RTP300 (Rigaku Co., Japan) X-ray diffractometer operating at $50 \mathrm{kV}$ and $200 \mathrm{~mA}$. Nickel-filtered $\mathrm{Cu} \mathrm{K}_{\alpha}$ radiation was used for the measurements, along with an angular range of $5<2 \theta<30^{\circ}$. The FT-IR spectra were measured at room temperature with hybrid nanofiber samples using a NEXUS670 FTIR spectrophotometer (Thermo Nicolet Co., USA). The spectra were recorded from 750 to $4000 \mathrm{~cm}^{-1}$ at a resolution of $4 \mathrm{~cm}^{-1}$. The mechanical behavior of resultant hybrid nanofibers mats was determined by a universal testing machine (TENSILON RTC1250A, A\&D Company, Ltd, Japan) under a crosshead speed $5.0 \mathrm{~mm} / \mathrm{min}$ at room temperature. In according with ASTM D-638, the specimens were prepared in the form of a dumbbell-shape by compression molding form fiber mats and then at least five specimens were tested for tensile behavior and the average values were reported. Two parameters were determined from each stress-strain curve: Young's modulus and tensile strength. Then the values of Young's modulus for resultant hybrid nanofibers were calculated from the initial slope of stressstrain curves.

\section{Results and discussion \\ 3.1. Morphologies of $\mathrm{CA} /$ graphene and $\mathrm{CA} /$ graphene-COOH nanofibers}

SEM images (Figure 1) and average fiber diameters (Figure 2) for pure CA and graphene or graphene$\mathrm{COOH}$ incorporated $\mathrm{CA}$ nanofibers were taken in order to study the changes of average fiber diameters on different loading of graphene or graphene- $\mathrm{COOH}$ into the CA nanofibers. It was observed that the diameters of CA hybrid nanofibers largely decreased as increasing the graphene or graphene- $\mathrm{COOH}$ contents, typically ranging from $580 \pm 200 \mathrm{~nm}$ for pure CA nanofibers to about $290 \pm 75 \mathrm{~nm}$ for both $4.0 \mathrm{wt} \%$ graphene/CA or $4.0 \mathrm{wt} \%$ graphene- $\mathrm{COOH} / \mathrm{CA}$ nano-

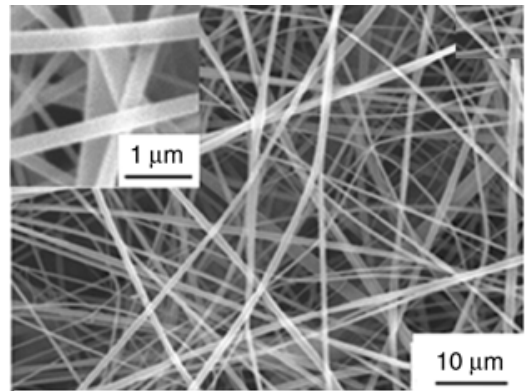

a)

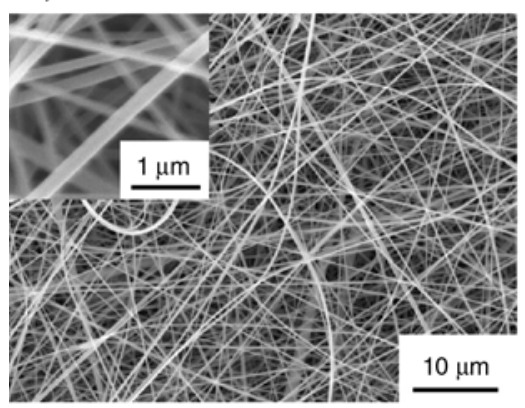

d)

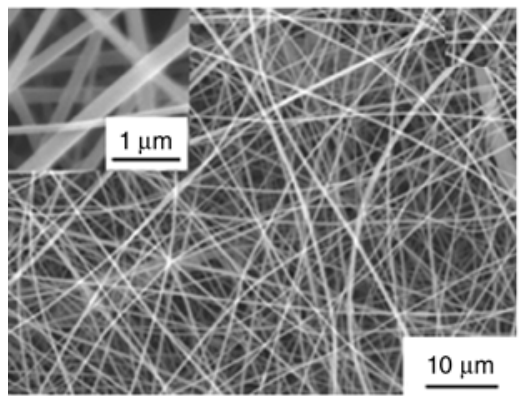

g)

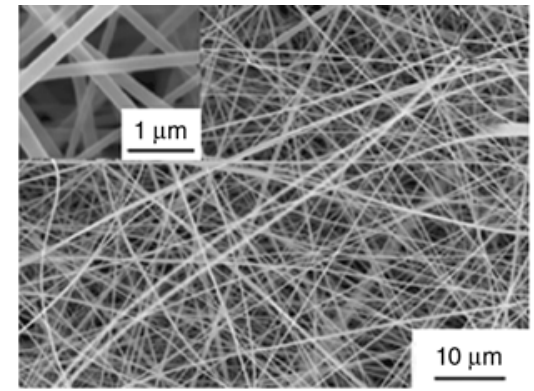

b)

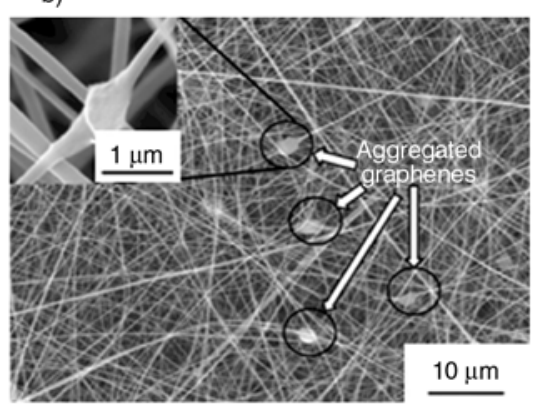

e)

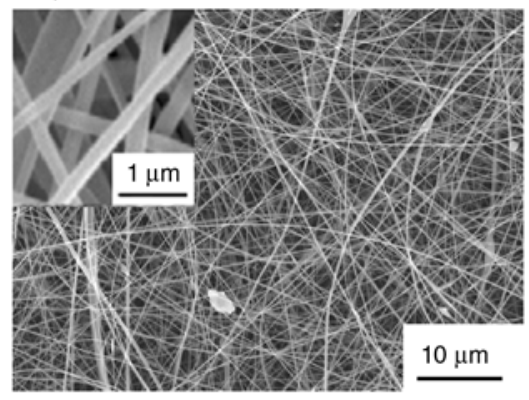

h)

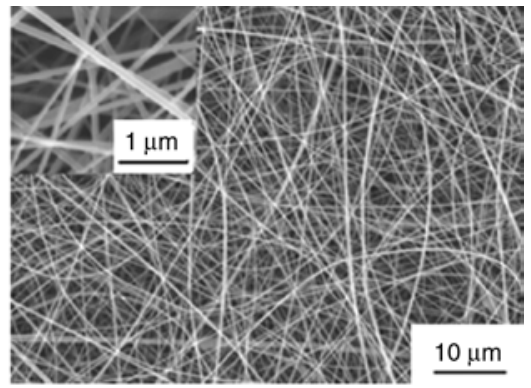

c)

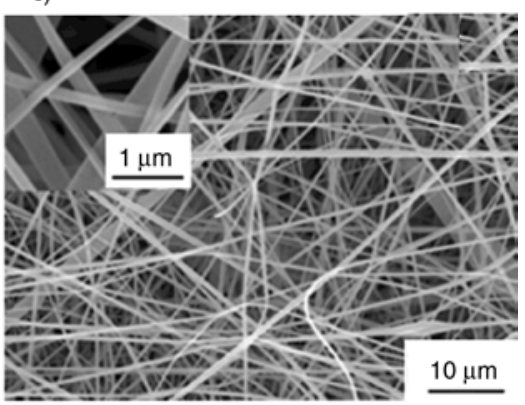

f)

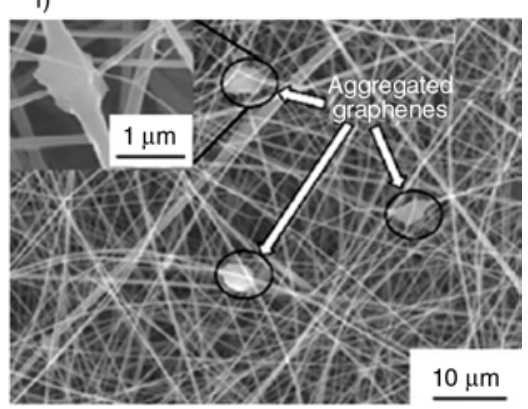

i)

Figure 1. SEM micrographs of pure CA (a), CA/graphene - (b) $1.0 \mathrm{wt} \%$, (c) $3.0 \mathrm{wt} \%$, (d) $4.0 \mathrm{wt} \%$, (e) $5.0 \mathrm{wt} \%$, and $\mathrm{CA} /$ graphene-COOH - (f) $1.0 \mathrm{wt} \%$, (g) $3.0 \mathrm{wt} \%$, (h) $4.0 \mathrm{wt} \%$, (i) $5.0 \mathrm{wt} \%$ nanofibers 


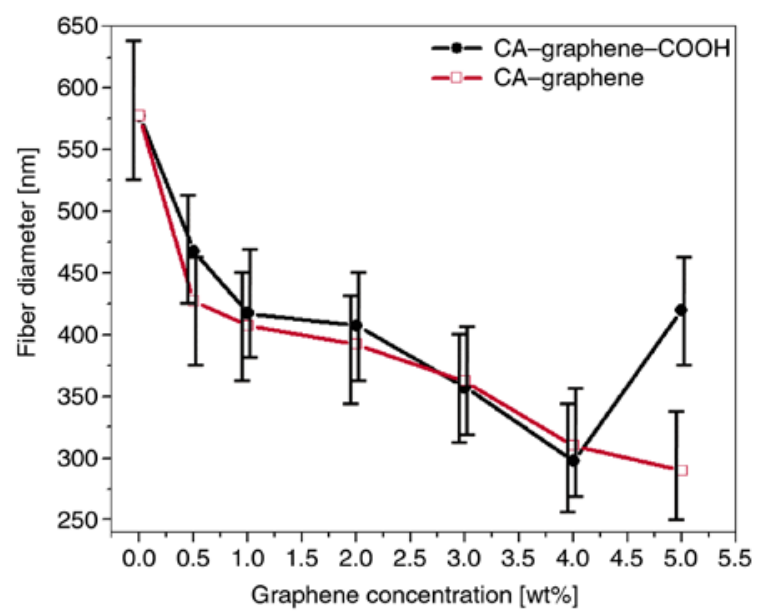

Figure 2. Distribution of fiber diameters for pure CA, CA/ graphene, and $\mathrm{CA} /$ graphene- $\mathrm{COOH}$ nanofibers prepared from different weight ratios of graphene or graphene- $\mathrm{COOH}$

fibers, respectively. The diameter of nanofiber was given as the average of more than 50 measurements. This can be attributed to an increased conductivity of the CA solutions blended with graphene or graphene- $\mathrm{COOH}$, which resulted in the formation of thinner fibers (Figure 2) [31]. This result also well coincided with those obtained in our previous works [32]. That is, the fiber diameter of graphene incorporated CA nanofibers gradually decreased until

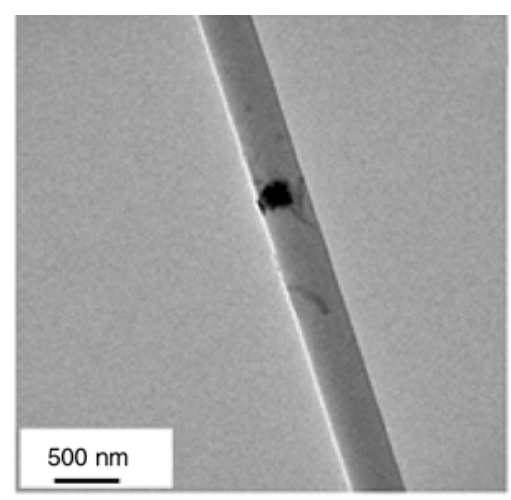

a)

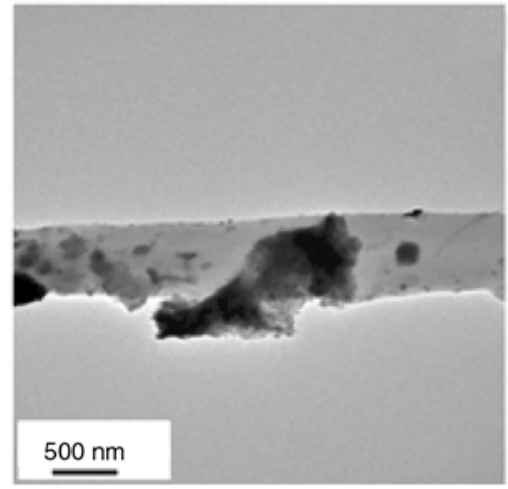

c) graphene concentration increased up to $5.0 \mathrm{wt} \%$. The fiber diameter of $\mathrm{CA} / \mathrm{graphene}$ nanofibers at graphene content $=5.0 \mathrm{wt} \%$ was about $270 \pm 80 \mathrm{~nm}$. On the other hand, the $\mathrm{CA} /$ graphene- $\mathrm{COOH}$ nanofibers exhibited the smallest fiber diameter $(\sim 290 \pm 75 \mathrm{~nm})$ at graphene- $\mathrm{COOH}$ contents $=$ $4.0 \mathrm{wt} \%$. When the graphene contents further increased to $5.0 \mathrm{wt} \%$, the average diameter increased to $440 \pm 70 \mathrm{~nm}$ consequently. Such hybrid nanofibers formed under this condition were not uniform due to the formation of few droplets and beads via severe graphene aggregations (Figure 1i). As a result, it confirmed that at higher graphene or graphene$\mathrm{COOH}$ contents the formation of continuous hybrid nanofibers was forbidden due to incapability to preserve the stable flow of the polymeric solution at the tip of the needle [32]. The formation of beads may suggest that the graphene- $\mathrm{COOH}$ and graphene at such higher concentration are not evenly dispersed in the CA solution.

In order to investigate the dispersions of graphene and graphene- $\mathrm{COOH}$ into the nanofibers, TEM images were taken for $\mathrm{CA} /$ graphene and $\mathrm{CA} /$ graphene- $\mathrm{COOH}$ nanofibers. As seen in Figures $3 \mathrm{a}$ and $3 \mathrm{~b}$, the morphologies showed that the graphene or graphene- $\mathrm{COOH}$ (content $\sim 4.0 \mathrm{wt} \%$ ) were well

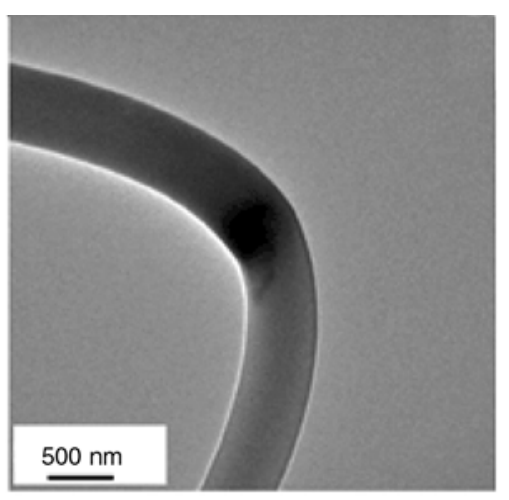

b)

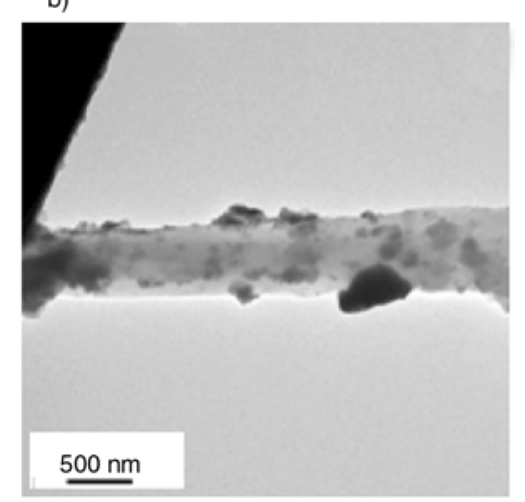

d)

Figure 3. TEM micrographs of graphene - (a) $4.0 \mathrm{wt} \%$, (c) $5.0 \mathrm{wt} \%$, and graphene-COOH - (b) $4.0 \mathrm{wt} \%$, (d) $5.0 \mathrm{wt} \%$ incorporated CA hybrid nanofibers. The scale bar is $500 \mathrm{~nm}$. 
embedded in the hybrid nanofibers during electrospinning process. This could be due to higher electrostatic fields during electrospinning process and are expected to result in a good incorporation of the graphene or graphene- $\mathrm{COOH}$ into the nanofibers [32]. On the other hand, as seen in Figures $3 c$ and $3 \mathrm{~d}$, the CA nanofibers with graphene or graphene$\mathrm{COOH}$ contents of $5.0 \mathrm{wt} \%$ exhibited severe aggregation of graphene or graphene- $\mathrm{COOH}$, aggregates are formed on their surfaces as well as inside of the fibers.

\subsection{FT-IR spectral studies}

In order to investigate the specific interactions of graphene or graphene- $\mathrm{COOH}$ with CA matrix, FTIR spectral studies were carried out for pure $\mathrm{CA}$ and graphene or graphene- $\mathrm{COOH}$ incorporated $\mathrm{CA}$ hybrid nanofibers (Figure 4). FT-IR spectrum of pure CA shows characteristic peaks at 1738,1369 and $1225 \mathrm{~cm}^{-1}$ due to the $v_{\mathrm{C}=\mathrm{O}}, v_{\mathrm{C}-\mathrm{CH}_{3}}$ and $v_{\mathrm{C}-\mathrm{O}-\mathrm{C}}$ stretching, respectively. In Figure 4b, FT-IR spectra of the graphene- $\mathrm{COOH}$ incorporated $\mathrm{CA}$ hybrid nanofibers revealed the presence of functional groups whose absorption frequencies correspond to $\mathrm{C}=\mathrm{O}$ (slightly shifted from 1738 to $1734 \mathrm{~cm}^{-1}$ ). The absorption band broadening of carboxyl groups for $\mathrm{CA} /$ graphene- $\mathrm{COOH}$ samples was also observed, which indicates hydrogen bonding interactions between CA matrix and graphene- $\mathrm{COOH}$. The shift in the absorption band of the hybrid nanofibers strongly suggests strong interactions between - $\mathrm{COOH}$ groups of graphene- $\mathrm{COOH}$ and $\mathrm{C}=\mathrm{O}$ groups of CA via hydrogen bonding. However, the IR spectra of pure graphene incorporated CA hybrid nanofibers (Figure 4a) showed no significant shift in the peaks, suggesting no interaction between graphene and CA molecules [33].

\subsection{Raman spectral studies}

Raman spectroscopy was recorded, in order to study the interfacial interactions between CA molecular chains and graphene or graphene- $\mathrm{COOH}$ nano-
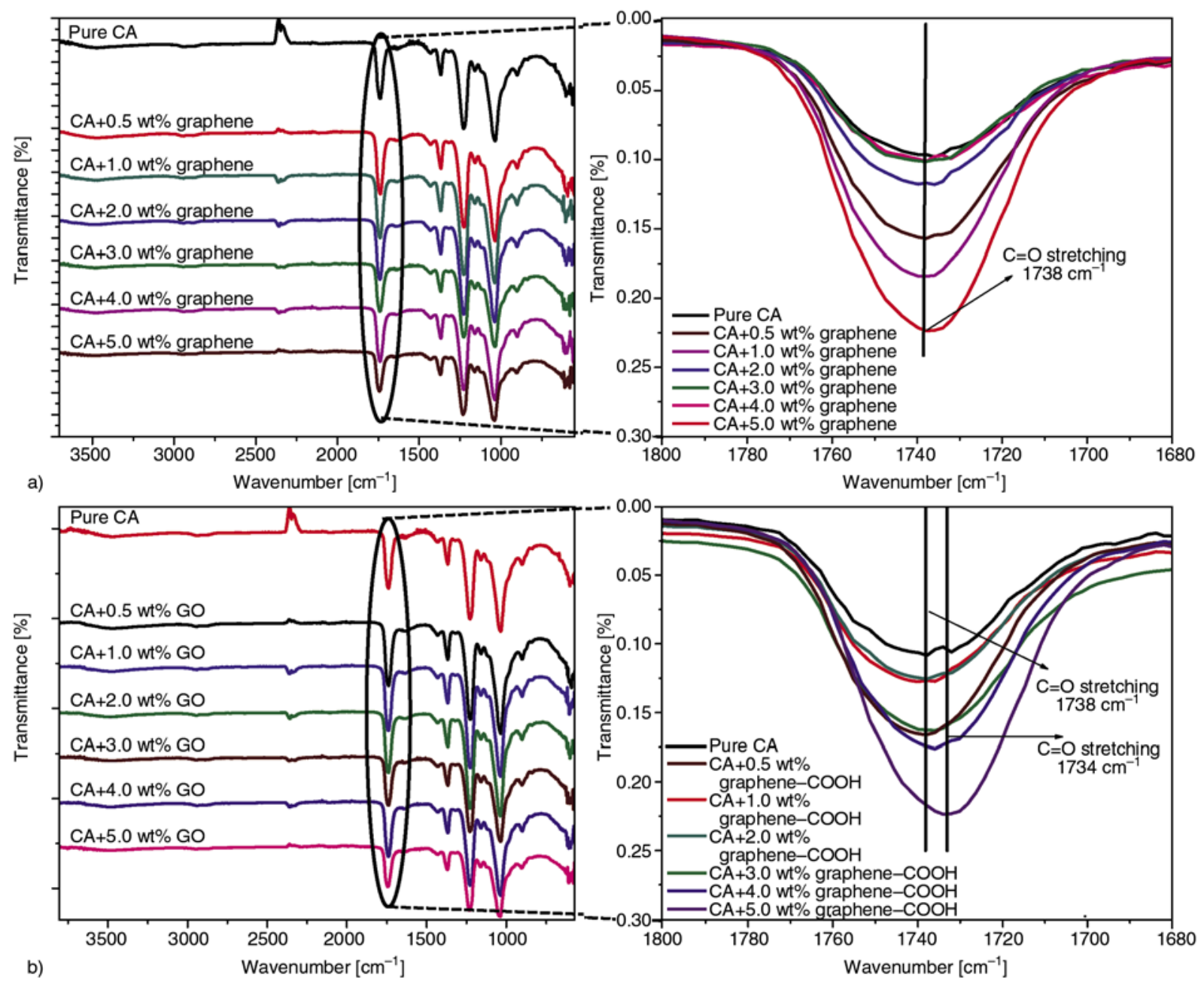

Figure 4. FT-IR spectra of graphene (a) and graphene-COOH (b) incorporated CA hybrid nanofibers 

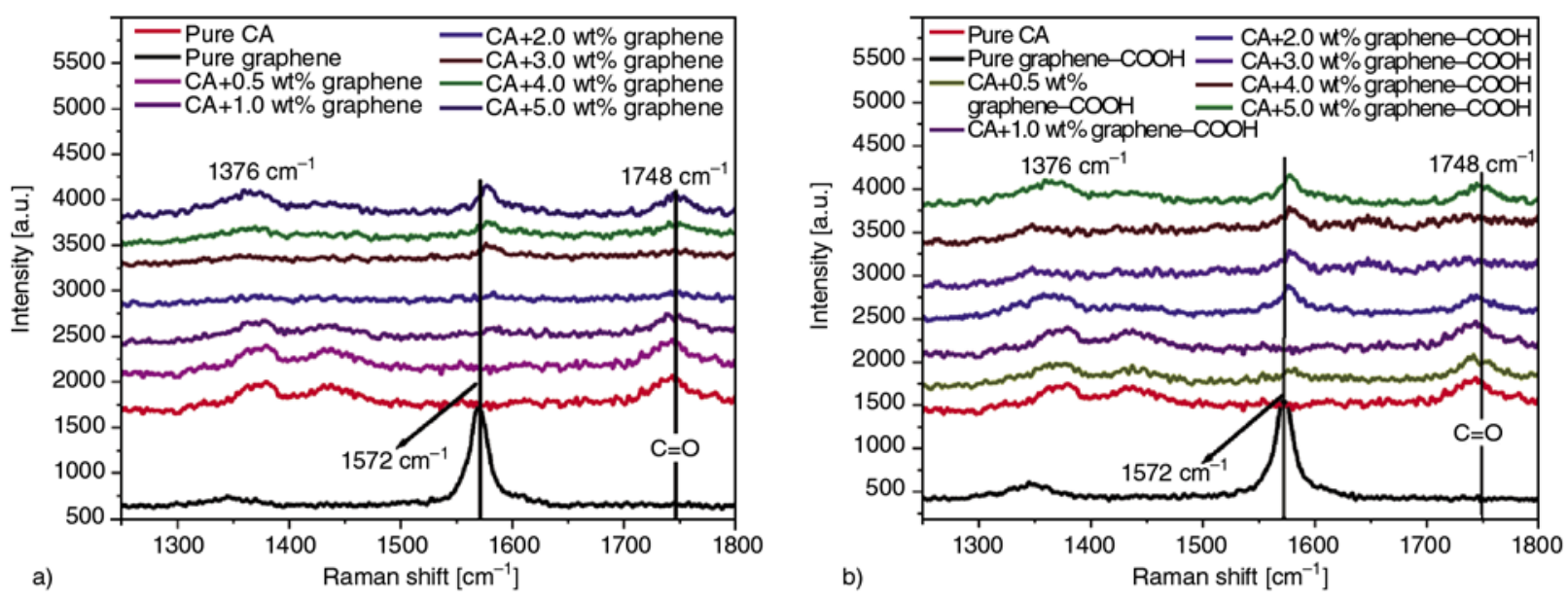

Figure 5. Raman spectra of graphene (a) and graphene-COOH (b) incorporated CA hybrid nanofibers

additives in the resultant hybrid CA nanofibers (Figure 5). In Figure 5, Raman spectra of the pure CA nanofibers showed two characteristic bands at 1376 and $1748 \mathrm{~cm}^{-1}$ due to $-\mathrm{CH}_{3}$ (anti-symmetric deformation vibrations of the methyl groups) and $-\mathrm{C}=\mathrm{O}$ vibrations, respectively. Similarly, Raman spectra of the both $\mathrm{CA} /$ graphene and CA/graphene$\mathrm{COOH}$ hybrid resultant nanofibers also showed the same characteristic bands at 1376 and $1748 \mathrm{~cm}^{-1}$. Furthermore, a new band at $1572 \mathrm{~cm}^{-1}$ (corresponding to $\mathrm{G}$ band of graphene) was observed except for pure CA nanofiber, suggesting that the graphene or graphene-COOH were well incorporated into the CA fibers during electrospinning [34]. Such $G$ band of graphene or graphene- $\mathrm{COOH}$ is red-shifted by about $6 \mathrm{~cm}^{-1}$ compared with those of pure graphene and graphene- $\mathrm{COOH}$. There may be several reasons for this which include 1) an enhanced specific surface area of graphene and graphene- $\mathrm{COOH}$ [35], 2) the rough/wrinkled surface texture [36] of graphene and graphene- $\mathrm{COOH}$ which can lead to a mechanical interlocking, and 3) the abundance of defects [37] in graphene and graphene- $\mathrm{COOH}$ which may provide chemical handles for good adhesion with CA polymer chains. The shift in the peak at $1572 \mathrm{~cm}^{-1}$ also confirms that there is a good adhesion and stress transfer between the CA polymer chains and the graphene or graphene- $\mathrm{COOH}$ nanoadditives, suggesting the hydrogen bonding interactions between the $\mathrm{C}=\mathrm{O}$ functional groups of $\mathrm{CA}$ and $-\mathrm{COOH}$ groups of graphene- $\mathrm{COOH}$, which also well coincided with the previous FT-IR data. It is therefore expected that the graphene or graphene$\mathrm{COOH}$ incorporated $\mathrm{CA}$ nanofibers show good
Young's modulus when compared with that of pure CA nanofibers.

\subsection{Wide angle $X$-ray diffraction}

In order to explain the interfacial interaction and the dispersion/incorporation of carbon nanomaterials into the CA matrix, WAXD was taken for pure CA and graphene or graphene- $\mathrm{COOH}$ incorporated $\mathrm{CA}$ hybrid nanofibers (Figure 6). The pure CA exhibited typical crystalline peaks at 8.7 and $17.2^{\circ}$, corresponding to the (110) and (200) reflections, as seen in Figure 6. It could be also seen from Figure 6, as increasing the graphene or graphene- $\mathrm{COOH}$ contents, the peak intensity at $8.7^{\circ}$ decreased first and then increased again. That is, in case of the CA/ graphene- $\mathrm{COOH}$ hybrid nanofibers the peak intensity at $8.7^{\circ}$ started to increase above graphene$\mathrm{COOH}=2.0 \mathrm{wt} \%$, while the $\mathrm{CA} /$ graphene hybrid nanofibers increased above graphene $=3.0 \mathrm{wt} \%$. Such increased peak intensity revealed enhanced crystallinity of CA polymer chains, suggesting that the incorporated graphene and graphene- $\mathrm{COOH}$ might act as a heterogeneous nucleation points, and thus the crystallinity of the CA was improved [38]. Besides, it might be attributed to enhanced alignment of the CA crystals, which was induced by increased solution conductivity of the $\mathrm{CA} /$ graphene and $\mathrm{CA} /$ graphene- $\mathrm{COOH}$ solutions during the electrospinning process [39]. However, at higher loading $(5.0 \mathrm{wt} \%)$, the graphene or graphene- $\mathrm{COOH}$ tend to aggregate and therefore the CA and the graphene or graphene- $\mathrm{COOH}$ are to be separated from each other, which results in an increased peak intensity at $26.5^{\circ}$, corresponding to the (002) reflec- 

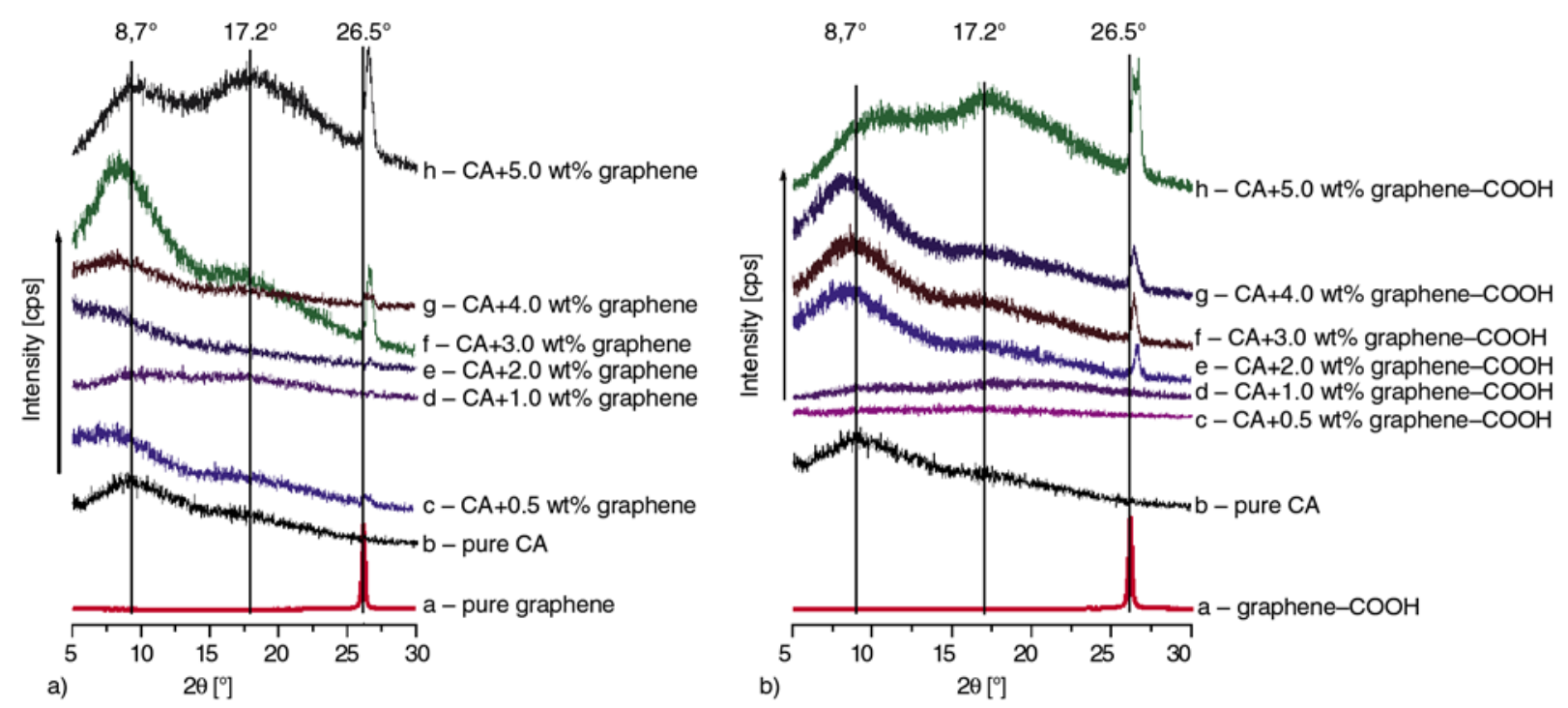

Figure 6. WAXD patterns of graphene (a) and graphene- $\mathrm{COOH}(\mathrm{b})$ incorporated CA hybrid nanofibers

tion of the incorporated graphene and graphene$\mathrm{COOH}$, in both $\mathrm{CA} /$ graphene and $\mathrm{CA} /$ graphene$\mathrm{COOH}$ hybrid nanofibers, as seen in Figures $6 \mathrm{a}(\mathrm{h})$ and $6 \mathrm{~b}(\mathrm{~h})$. As expected, the peak intensity at $26.5^{\circ}$ became evident gradually as the graphene or graphene- $\mathrm{COOH}$ contents increased. In addition, such peak intensity at lower loading of graphene or graphene- $\mathrm{COOH}$ disappeared (at loading contents ranging from 0.5 to $1.0 \mathrm{wt} \%$ ), suggesting the disorder and loss of structure regularity of the graphene and graphene-COOH. Thus, the graphene and graphene- $\mathrm{COOH}$ are considered to be well-dispersed at the molecular level into the CA matrix [38]. Moreover, Figure 6 showed the shift in the peak at $26.5^{\circ}$ for graphene- $\mathrm{COOH}$ incorporated CA nanofibers (approximately from 26.5 to $27.1^{\circ}$ ) when compared to that of graphene incorporated CA hybrid nanofibers (very little shift). It may be due to the fact that $-\mathrm{COOH}$ group of graphene effectively acted as nucleation center, which therefore resulted in higher Young's modulus of CA/graphene- $\mathrm{COOH}$ hybrid nanofibers [39]. Furthermore, slight shift in the peak at $8.7^{\circ}$ (from 8.7 to $8.3^{\circ}$ ) also strongly revealed that $\mathrm{CA}$ matrix was effectively disturbed by graphene and graphene- $\mathrm{COOH}[38]$.

\subsection{Mechanical properties}

Figure 7 shows Young's modulus of pure CA nanofiber, $\mathrm{CA} /$ graphene nanofibers and $\mathrm{CA} /$ graphene$\mathrm{COOH}$ nanofibers as a function of graphene or graphene- $\mathrm{COOH}$ contents at room temperature. Young's modulus of graphene- $\mathrm{COOH}$ incorporated CA hybrid nanofibers increased gradually as increas-

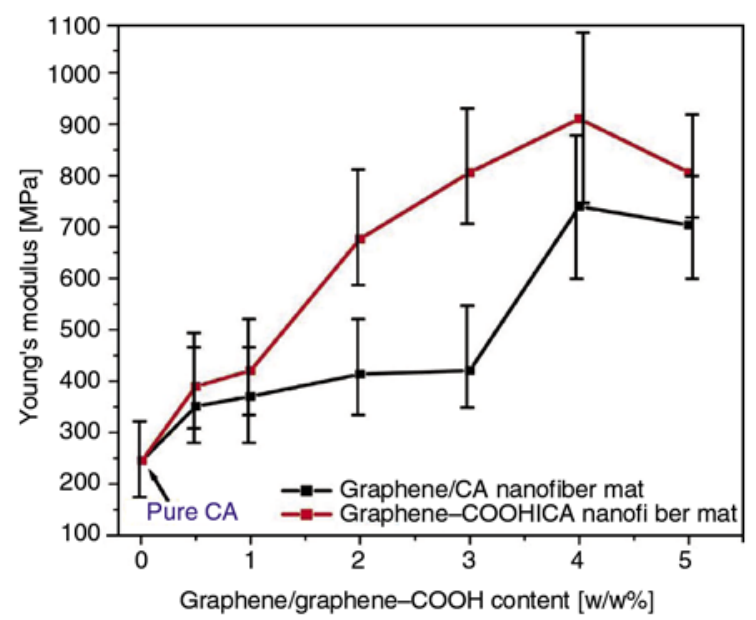

Figure 7. Young's modulus of CA/graphene nanofibers and

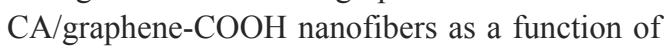
graphene or graphene- $\mathrm{COOH}$ contents at room temperature

ing the graphene- $\mathrm{COOH}$ contents. In particular, the $\mathrm{CA} /$ graphene- $\mathrm{COOH}$ hybrid nanofiber mat with $4.0 \mathrm{wt} \%$ graphene-COOH showed the highest Young's modulus, which was approximately 3.7 times higher than that of pure CA nanofiber mat ( $\sim 245.5 \mathrm{MPa}$, see Table 1), suggesting that mechanical properties of such hybrid nanofibers [40] were increased with increasing the amounts of graphene$\mathrm{COOH}$ nano-additives. A similar tendency was also observed for $\mathrm{CA} /$ graphene hybrid nanofibers. Young's modulus of CA hybrid nanofiber mat with $4 \mathrm{wt} \%$ graphene was found to be $739.8 \mathrm{MPa}$, which was about 3 times higher than that of pure CA nanofiber mat (Table 1). However, at $5 \mathrm{wt} \%$ graphene or graphene- $\mathrm{COOH}$ contents, Young's modulus of the hybrid CA nanofibers started to decrease again. This 
Table 1. Young's modulus of CA/graphene and CA/ graphene-COOH nanofibers

\begin{tabular}{|c|c|c|}
\hline $\begin{array}{c}\text { Weight percentages of } \\
\text { graphene/graphene-COOH }\end{array}$ & $\begin{array}{c}\text { Young's modulus of graphene/CA } \\
\text { [MPa] }\end{array}$ & $\begin{array}{c}\text { Young's modulus of graphene-COOH/CA } \\
{[\mathbf{M P a}]}\end{array}$ \\
\hline 0 & \multicolumn{2}{|c|}{$247 \pm 102$} \\
\hline 0.5 & $351.1 \pm 130$ & $389.5 \pm 140$ \\
\hline 1.0 & $370.5 \pm 160$ & $420.6 \pm 210$ \\
\hline 2.0 & $413.7 \pm 200$ & $676.9 \pm 310$ \\
\hline 3.0 & $420.6 \pm 280$ & $806.0 \pm 380$ \\
\hline 4.0 & $739.8 \pm 350$ & $910.6 \pm 460$ \\
\hline 5.0 & $703.7 \pm 330$ & $805.7 \pm 380$ \\
\hline
\end{tabular}

may be due to the beads formed on fiber's surface and hence a poorer mechanical performance of the nanofiber mats. Although the added amounts of graphene or graphene-COOH were the same, graphene- $\mathrm{COOH}$ showed higher Young's modulus values (Figure 7). It certainly demonstrated that the hydrogen-bonding between- $\mathrm{COOH}$ groups in the graphene- $\mathrm{COOH}$ and $-\mathrm{C}=\mathrm{O}$ groups in the $\mathrm{CA}$ molecules was formed at the interfaces in the CA hybrid nanofibers, and thereby resulted in the higher Young's modulus of CA/graphene- $\mathrm{COOH}$ nanofiber membranes [41], which is also well correlated with the results of FT-IR, WAXD and Raman analysis.

\section{Conclusions}

We have prepared the pure CA, CA/graphene and $\mathrm{CA} /$ graphene- $\mathrm{COOH}$ nanofibers by electrospinning process, and studied the effects of graphene or graphene- $\mathrm{COOH}$ contents on the morphologies, microstructures and mechanical properties of the resultant $\mathrm{CA}$ hybrid nanofibers. SEM analysis demonstrated that the diameters of CA hybrid nanofibers were dramatically decreased as graphene or graphene- $\mathrm{COOH}$ contents increased, typically ranging from $580 \pm 200 \mathrm{~nm}$ for pure CA nanofibers to about $290 \pm 75 \mathrm{~nm}$ for both $4.0 \mathrm{wt} \%$ graphene/CA or $4.0 \mathrm{wt} \%$ graphene-COOH/CA nanofibers, respectively. This can be attributed to the increased conductivity which resulted in the formation of thinner fibers. Moreover, the hybrid nanofibers electrospun from the CA solution with $4 \mathrm{wt} \%$ graphene or graphene- $\mathrm{COOH}$ contents exhibited the smallest fiber diameter, and the fiber diameter distributions were also narrower, suggesting good distribution of the graphene or graphene-COOH onto the CA nanofiber matrix, which was also confirmed by TEM analysis. Specific interactions between $-\mathrm{COOH}$ groups in acid-treated graphene and $\mathrm{C}=\mathrm{O}$ groups in $\mathrm{CA}$ via hydrogen bonding were demonstrated by
FT-IR and Raman spectroscopic analysis. The broadening and slight shifting from 1738 to $1734 \mathrm{~cm}^{-1}$ of $\mathrm{C}=\mathrm{O}$ absorption band in the $\mathrm{CA} /$ graphene- $\mathrm{COOH}$ samples clearly indicated strong interactions between $-\mathrm{COOH}$ groups of graphene- $\mathrm{COOH}$ and $\mathrm{C}=\mathrm{O}$ groups of CA via hydrogen bonding. WAXD results also confirmed the good incorporation of graphene or graphene- $\mathrm{COOH}$ and good interfacial interaction between CA matrix and graphene or graphene$\mathrm{COOH}$ nano-nano-additives. In addition, it was found that the CA hybrid nanofiber mat with $4.0 \mathrm{wt} \%$ graphene- $\mathrm{COOH}$ showed the highest Young's modulus, which was approximately 3.7 times higher than that of pure CA nanofiber mat $(\sim 245.5 \mathrm{MPa})$. It suggested that the brittleness of such hybrid nanofibers increased with increasing the amounts of graphene- $\mathrm{COOH}$ additives.

\section{Acknowledgements}

This work was supported by Grant-in-Aid for Global COE Program by the Ministry of Education, Culture Sports Science, and Technology, Japan. This paper was supported by research funds of Chonbuk National University in 2012.

\section{References}

[1] Matthews J. A., Wnek G. E., Simpson D. G., Bowlin G. L.: Electrospinning of collagen nanofibers. Biomacromolecules, 3, 232-238 (2002).

DOI: $10.1021 / \mathrm{bm} 015533 \mathrm{u}$

[2] Singh R. P., Pandey J. K., Rutot D., Degée Ph., Dubois $\mathrm{Ph}$.: Biodegradation of poly( $\varepsilon$-caprolactone $) /$ starch blends and composites in composting and culture environments: The effect of compatibilization on the inherent biodegradability of the host polymer. Carbohydrate Research, 338, 1759-1769 (2003).

DOI: 10.1016/S0008-6215(03)00236-2

[3] Ohgo K., Zhao C., Kobayashi M., Asakura T.: Preparation of non-woven nanofibers of Bombyx mori silk, Samia cynthia ricini silk and recombinant hybrid silk with electrospinning method. Polymer, 44, 841-846 (2003).

DOI: $10.1016 / \mathrm{S} 0032-3861(02) 00819-4$ 
[4] Wei K., Kim B-S., Abe K., Chen G. Q., Kim I-S.: Fabrication and fibroblast attachment property of regenerated silk fibroin/tetramethoxysilane nanofibrous biocomposites. Advanced Engineering Materials, 14, B258-B265 (2012).

DOI: 10.1002 /adem.201180079

[5] Geng X., Kwon O-H., Jang J.: Electrospinning of chitosan dissolved in concentrated acetic acid solution. Biomaterials, 26, 5427-5432 (2005).

DOI: 10.1016/j.biomaterials.2005.01.066

[6] Kim B-S., Kim I-S.: Recent nanofiber technologies. Polymer Reviews, 51, 235-238 (2011).

DOI: $10.1080 / 15583724.2011 .599507$

[7] Kim C-W., Kim D-S., Kang S-Y., Marquez M., Joo Y. L.: Structural studies of electrospun cellulose nanofibers. Polymer, 47, 5097-5107 (2006). DOI: $10.1016 /$ j.polymer.2006.05.033

[8] Sassi J-F., Chanzy H.: Ultrastructural aspects of the acetylation of cellulose. Cellulose, 2, 111-127 (1995). DOI: $10.1007 / \mathrm{BF} 00816384$

[9] Khatri Z., Wei K., Kim B-S., Kim I-S.: Effect of deacetylation on wicking behavior of co-electrospun cellulose acetate/polyvinyl alcohol nanofibers blend. Carbohydrate Polymers, 87, 2183-2188 (2012). DOI: $10.1016 /$ j.carbpol.2011.10.046

[10] Tserki V., Zafeiropoulus N. E., Simon F., Panayiotou C.: A study of the effect of acetylation and propionylation surface treatments on natural fibres. Composites Part A: Applied Science and Manufacturing, 36, 1110 1118 (2005).

DOI: $10.1016 /$ j.compositesa.2005.01.004

[11] Filho G. R., Monteiro D. S., da Silva Meireles C., de Assuncao R. M. N., Cerqueira D. A., Barud H. S., Ribeiro S. J. L., Messadeq Y.: Synthesis and characterization of cellulose acetate produced from recycled newspaper. Carbohydrate Polymers, 73, 74-82 (2008). DOI: $10.1016 / \mathrm{j}$. carbpol.2007.11.010

[12] Edgar K. J., Buchanan C. M., Debenham J. S., Rundquist P. A., Seiler B. D., Shelton M. C., Tindall D.: Advances in cellulose ester performance and application. Progress in Polymer Science, 26, 1605-1688 (2001).

DOI: 10.1016/S0079-6700(01)00027-2

[13] Biswas A., Shogren R. L., Willett J. L.: Solvent-free process to esterify polysaccharides. Biomacromolecules, 6, 1843-1845 (2005).

DOI: $10.1021 / \mathrm{bm} 0501757$

[14] Barud H. S., de Araújo A. M., Santos D. B., de Assunção R. M. N., Meireles C. S., Cerqueira D. A., Filho G. R., Ribeiro C. A., Messadeq Y., Ribeiro S. J. L.: Thermal behavior of cellulose acetate produced from homogeneous acetylation of bacterial cellulose. Thermochimica Acta, 471, 61-69 (2008).

DOI: $10.1016 /$ j.tca.2008.02.009
[15] Yu D-G., Yu J-H., Chen L., Williams G. R., Wang X.: Modified coaxial electrospinning for the preparation of high-quality ketoprofen-loaded cellulose acetate nanofibers. Carbohydrate Polymers, 90, 1016-1023 (2012).

DOI: $10.1016 /$ j.carbpol.2012.06.036

[16] Yu D-G., Li X-Y., Wang X., Chian W., Liao Y-Z., Li Y.: Zero-order drug release cellulose acetate nanofibers prepared using coaxial electrospinning. Cellulose, 20, 379-389 (2013). DOI: $10.1007 / \mathrm{s} 10570-012-9824-\mathrm{Z}$

[17] Shin M. K., Lee B., Kim S. H., Lee J. A., Spinks G. M., Gambhir S., Wallace G. G., Kozlov M. E., Baughman R. H., Kim S. J.: Synergistic toughening of composite fibres by self-alignment of reduced graphene oxide and carbon nanotubes. Nature Communications, 3, 650/1-650/8 (2012).

DOI: $10.1038 /$ ncomms 1661

[18] Dalton A. B., Collins S., Muñoz E., Razal J. M., Ebron V. H., Ferraris J. P., Coleman J. N., Kim B. G., Baughman R. H.: Super-tough carbon-nanotube fibres. Nature, 423, 703-709 (2003).

DOI: $10.1038 / 423703 a$

[19] Lachman N., Bartholome C., Miaudet P., Maugey M., Poulin P., Wagner H. D.: Raman response of carbon nanotube/PVA fibers under strain. Journal of Physical Chemistry C, 113, 4751-4754 (2009).

DOI: $10.1021 / j p 900355 \mathrm{k}$

[20] Dalton A. B., Collins S., Razal J., Munoz E., Ebron V. H., Kim B. G., Coleman J. N., Ferraris J. P., Baughman R. H.: Continuous carbon nanotube composite fibers: Properties, potential applications, and problems. Journal of Materials Chemistry, 14, 1-3 (2004).

DOI: 10.1039/B312092A

[21] Baltopoulos A., Athanasopoulos N., Fotiou I., Vavouliotis A., Kostopoulos V.: Sensing strain and damage in polyurethane-MWCNT nano-composite foams using electrical measurements. Express Polymer Letters, 7, 40-54 (2013).

DOI: $10.3144 /$ expresspolymlett.2013.4

[22] Villmow T., Pötschke P., Pegel S., Häussler L., Kretzschmar B.: Influence of twin-screw extrusion conditions on the dispersion of multi-walled carbon nanotubes in a poly(lactic acid) matrix. Polymer, 49, 3500-3509 (2008).

DOI: $10.1016 /$ j.polymer.2008.06.010

[23] Bang H. S., Gopiraman M., Kim B-S., Kim S-H., Kim I-S.: Effects of $\mathrm{pH}$ on electrospun PVA/acid-treated MWNT composite nanofibers. Colloids and Surfaces A: Physicochemical and Engineering Aspects, 409, 112117 (2012).

DOI: $10.1016 /$ j.colsurfa.2012.05.046 
[24] Ohta T., Ito T., Shimizu M., Tauchi L., Nguyen-Tran H-D., Park J-C., Kim B-S., Kim I-S., Ohta K.: Development of novel synthetic method of carbon nanotubes from electrospun polystyrene fibers by using microwave heating. Polymers for Advanced Technologies, 22, 2653-2658 (2011).

DOI: $10.1002 /$ pat.1723

[25] Coleman J. N., Cadek M., Blake R., Nikolosi V., Ryan K. P., Belton C., Fonseca A., Nagy J. B., Gun'ko Y. K., Blau W. J.: High performance nanotube-reinforced plastics: understanding the mechanism of strength increase. Advanced Functional Materials, 14, 791-798 (2004). DOI: $10.1002 / \mathrm{adfm} .200305200$

[26] Moazzami Gudarzi M., Sharif F.: Enhancement of dispersion and bonding of graphene-polymer through wet transfer of functionalized graphene oxide. Express Polymer Letters, 6, 1017-1031 (2012).

DOI: $10.3144 /$ expresspolymlett.2012.107

[27] Garg P., Singh B. P., Kumar G., Gupta T., Pandey I., Seth R. K., Tandon R. P., Mathur R. B.: Effect of dispersion conditions on the mechanical properties of multi-walled carbon nanotubes based epoxy resin composites. Journal of Polymer Research, 18, $1397-$ 1407 (2011).

DOI: $10.1007 / \mathrm{s} 10965-010-9544-8$

[28] Lee C., Wei X., Kysar J. W., Hone J.: Measurement of the elastic properties and intrinsic strength of monolayer graphene. Science, 321, 385-388 (2008). DOI: 10.1126/science. 1157996

[29] Gómez-Navarro C., Burghard M., Kern K.: Elastic properties of chemically derived single graphene sheets. Nano Letters, 8, 2045-2049 (2008). DOI: $10.1021 / \mathrm{nl} 801384 \mathrm{y}$

[30] Balandin A. A., Ghosh S., Bao W. Z., Calizo I., Teweldebrhan D., Miao F., Lau C. N.: Superior thermal conductivity of single-layer graphene. Nano Letters, 8, 902-907 (2008).

DOI: $10.1021 / \mathrm{n} 10731872$

[31] Potts J. R., Dreyer D. R., Bielawski C. W., Ruoff R. S.: Graphene-based polymer nanocomposites. Polymer, 52, 5-25 (2011). DOI: $10.1016 /$ j.polymer.2010.11.042

[32] Wei K., Xia J-H., Kim B-S., Kim I-S.: Multiwalled carbon nanotubes incorporated Bombyx mori silk nanofibers by electrospinning. Journal of Polymer Research, 18, 579-585 (2011). DOI: $10.1007 / \mathrm{s} 10965-010-9451-\mathrm{Z}$
[33] Li M., Kim I-H., Jeong Y. G.: Cellulose acetate/multiwalled carbon nanotube nanocomposites with improved mechanical, thermal, and electrical properties. Journal of Applied Polymer Science, 118, 2475-2481 (2010). DOI: 10.1002/app.32591

[34] Tan P., Dimovski S., Gogotsi Y.: Raman scattering of non-planar graphite: Arched edges, polyhedral crystals, whiskers and cones. Philosophical Transactions of the Royal Society A: Mathematical, Physical and Engineering Sciences, 362, 2289-2310 (2004).

DOI: $10.1098 /$ rsta.2004.1442

[35] Kolmakov A., Dikin D. A., Cote L. J., Huang J., Abyaneh M. K., Amati M., Gregoratti L., Günther S., Kiskinova M.: Graphene oxide windows for in situ environmental cell photoelectron spectroscopy. Nature Nanotechnology, 6, 651-657 (2011). DOI: $10.1038 /$ nnano. 2011.130

[36] Rafiee M., Rafiee J., Wang Z., Song H., Yu Z-Z., Koratkar N.: Enhanced mechanical properties of nanocomposites at low graphene content. ACS Nano, 3, 3884-3890 (2009). DOI: $10.1021 / \mathrm{nn} 9010472$

[37] Rafiee J., Rafiee M. A., Yu Z-Z., Koratkar N.: Superhydrophobic to superhydrophilic wetting control in graphene films. Advanced Materials, 22, 2151-2154 (2010).

DOI: $10.1002 / \mathrm{adma} .200903696$

[38] Zhao X., Zhang Q., Chen D., Lu P.: Enhanced mechanical properties of graphene-based poly(vinyl alcohol) composites. Macromolecules, 43, 2357-2363 (2010). DOI: $10.1021 / \mathrm{ma902862u}$

[39] Chakoli A. N., Sui J., Amirian M., Cai W.: Crystallinity of biodegradable polymers reinforced with functionalized carbon nanotubes. Journal of Polymer Research, 18, 1249-1259 (2011). DOI: $10.1007 / \mathrm{s} 10965-010-9527-9$

[40] Huang X., Qi X., Boey F., Zhang H.: Graphene-based composites. Chemical Society Reviews, 41, 666-686 (2012). DOI: $10.1039 / \mathrm{C} 1 \mathrm{CS} 15078 \mathrm{~B}$

[41] Huang J., Liu L., Yao J.: Electrospinning of Bombyx mori silk fibroin nanofiber mats reinforced by cellulose nanowhiskers. Fibers and Polymers, 12, $1002-$ 1006 (2011). DOI: $10.1007 / \mathrm{s} 12221-011-1002-7$ 